\title{
Synthesis of DNA-templated fluorescent gold nanoclusters
}

\author{
Guiying Liu • Yong Shao $\cdot$ Kun Ma • Qinghua Cui • \\ Fei Wu $\cdot$ Shujuan Xu
}

Published online: 4 May 2012

(C) The Author(s) 2012. This article is published with open access at Springerlink.com

\begin{abstract}
Water-soluble and red-emitting gold nanoclusters (Au NCs) were synthesized with single-stranded DNA as a promising biotemplate and dimethylamine borane as a mild reductant. The fluorescent $\mathrm{Au}$ NCs can be formed in a weakly acidic aqueous solution that is free from the simultaneous formation of large nanoparticles. The cluster feature of the formed Au species has been revealed by fluorescence spectra, absorption spectra, and transmission electron microscopy. Additionally, DNA sequences could be used to tune the $\mathrm{Au} \mathrm{NCs}$ ' emissions. The as-prepared Au NCs display high stability at physiological $\mathrm{pH}$ condition, and thus, wide potential applications are anticipated for the biocompatible fluorescent $\mathrm{Au}$ NCs serving as nanoprobes in bioimaging and related fields.
\end{abstract}

Keywords Gold nanoclusters · Fluorescence · DNA · Dimethylamine borane $\cdot$ Template

\section{Introduction}

Decreasing the size of noble metal nanostructures (mainly $\mathrm{Au}$ and $\mathrm{Ag}$ ) down to less than $2 \mathrm{~nm}$ will produce nanoclusters (NCs) and restrict the motion of their free electrons in a very confined space that results in discrete electronic band structures. When the discrete band energies become

Electronic supplementary material The online version of this article (doi:10.1007/s13404-012-0049-6) contains supplementary material, which is available to authorized users.

G. Liu $\cdot$ Y. Shao $(\bowtie) \cdot$ K. Ma $\cdot$ Q. Cui $\cdot$ F. Wu $\cdot$ S. Xu

Zhejiang Key Laboratory for Reactive Chemistry on Solid Surfaces, Institute of Physical Chemistry, Zhejiang Normal University,

Jinhua 321004 Zhejiang, People's Republic of China

e-mail: yshao@zjnu.cn larger than thermal energies, the NCs will behave like molecules in respect of optical properties such as light absorption and emission. Au NCs have emerged as novel fluorescent nanomaterials because of their better performance in many aspects like biocompatibility, photostability, and non-toxicity relative to organic dyes and semiconductor quantum dots [1-4].

Fluorescent $\mathrm{Au}$ NCs have been prepared mainly in a bottom-up manner by the reduction of gold precursors in the presence of various templates such as macromolecules (dendrimers [5-9], proteins [10-24], poly-butadiene [25]), small molecules (histidine [26], carbohydrate [27], thiols [28-33], $N, N$-dimethylformamide [34, 35], penicillamine [36]), and even solid functional organisms (eggshell membrane [37]). Alternatively, top-down etching of preformed large nanoparticles down to desired NC sizes has received much attention due to many available synthetic strategies for the large nanoparticles. In this aspect, polyethylenimine [38], dihydrolipoic acid [39, 40], thiols [41-43], Good's buffers [44], cyclodextrins [45], and even hydrochloric acid [46] have been employed as effective etchants. Recently, large nanoparticles have been reported to be even fluorescent after being sensitized by thiols [47, 48].

It is widely accepted that the formation of stable Au NCs is controlled by a slow thermodynamic process for a narrow size distribution following their relative rapid formation [49] or by a cyclic process of growth and etching reactions around the most stable cluster species to form nearly monodisperse product distributions $[46,50]$. In addition, the optical properties of the $\mathrm{Au} \mathrm{NCs}$ are related to the ligands that protect them from aggregations [51] and redox state of the gold core $[52,53]$, or the gold core geometry tuned by the oxidation states [53]. On the basis of this mechanism understanding, many applications, for example, detections of $\mathrm{Hg}^{2+}[12-15,37,47], \mathrm{Cu}^{2+}[19,20,32], \mathrm{CN}^{-}$[17], $\mathrm{H}_{2} \mathrm{O}_{2}$ 
[18], glucose [24], and dopamine [21], and cell labeling or imaging [13, 23, 40, 48], have been achieved with Au NCs as reporters by direct or indirect reaction of the NCs' protecting ligands or gold cores with the species of interest. However, in comparison to the fruitful strategies for the DNA-templated synthesis and optical tunability of silver nanoclusters (Ag NCs) [54, 55], there are fewer reports for the successful synthesis of Au NCs with DNA as template. Recently, atomically monodisperse fluorescent $\mathrm{Au} \mathrm{NCs}$ were obtained by etching gold particles (either spheres or rods) with the assistance of DNA under sonication in water [56]. Due to the photosensitivity of Ag species, the most prominent advantage of DNA-templated $\mathrm{Au}$ NCs over Ag $\mathrm{NCs}$ in biocompatible applications would be the Au NCs' favorable stability. In this work, single-stranded DNA was first employed as an alternative template during reduction of Au precursor to produce Au NCs (see Fig. 1).

\section{Experimental}

Synthesis of fluorescent Au NCs

Twenty-three-mer DNAs with the sequences of 5'GAGGCGCTGCCYCCACCATGAGC-3' (named 23-Ys, $\mathrm{Y}=\mathrm{C}, \mathrm{A}, \mathrm{G}$, and $\mathrm{T}$ ) were synthesized by TaKaRa Biotechnology Co., Ltd. (Dalian, China). All the DNA samples were HPLC purified by the manufacturer. Other reagents were of analytical grade and used without further purification. Nanopure water (18.2 $\mathrm{m} \Omega$; Millipore Co., USA) was used in all experiments. In a typical experiment, chloroauric acid $\left(\mathrm{HAuCl}_{4}\right.$, Sigma Chemical Co., St. Louis, USA) solution was added to the single-stranded DNA solution in $20 \mathrm{mM}$ phosphate containing $1 \mathrm{mM}$ magnesium acetate (PBS) by an appropriate $\mathrm{HAuCl}_{4} / \mathrm{DNA}$ concentration ratio. After being thoroughly mixed, the solution was aged at room temperature for $10 \mathrm{~h}$ to allow for the completion of the interaction of $\mathrm{HAuCl}_{4}$ with DNA. Then, the freshly prepared dimethylamine borane (DMAB, Sigma Chemical Co., St. Louis, USA) solution was added to the aged $\mathrm{HAuCl}_{4} / \mathrm{DNA}$ solution, which was followed by another 36-h reaction at room temperature in the dark to produce fluorescent Au NCs. The resulting solutions were examined at room temperature $\left(22 \pm 1^{\circ} \mathrm{C}\right)$. For control experiments, sodium borohydride was used as the reductant to replace DMAB.

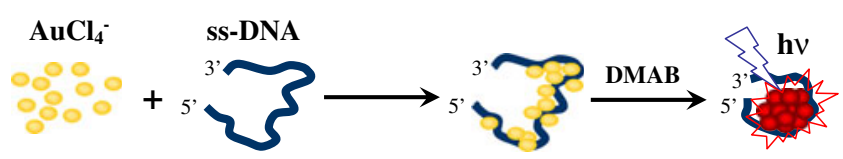

Fig. 1 Schematic illustration for the formation of Au NCs templated by DNA

\section{Characterization of fluorescent $\mathrm{Au} \mathrm{NCs}$}

Fluorescence spectra were acquired with a FLSP920 spectrofluorometer (Edinburgh Instruments Ltd., UK) at $22 \pm 1{ }^{\circ} \mathrm{C}$, equipped with a temperature-controlled circulator (Julabo, Germany). UV/vis absorption spectra were determined with a UV2550 spectrophotometer (Shimadzu Corp., Japan). Transmission electron microscopy (TEM) images were acquired on a JEOL 2010F transmission electron microscope at the acceleration voltage of $200 \mathrm{kV}$. The TEM samples were prepared by dropping a dispersion of the as-prepared Au NCs onto a $\mathrm{Cu}$ grid covered by a holey carbon film.

\section{Results and discussion}

Fluorescent $\mathrm{Au}$ NCs have been widely synthesized in a bottom-up manner by reduction of gold precursors that are associated with various biotemplates [10] such as bovine serum albumin [11], horseradish peroxidase [18], lysozyme [12], and transferrin protein [20]. Nevertheless, synthesis of $\mathrm{Au}$ NCs templated by DNA has rarely been reported maybe because of the weak association between the negatively charged DNA and commonly used precursor $\mathrm{AuCl}_{4}^{-}$. Here, we tried to qualify the right conditions to synthesize fluorescent Au NCs in the presence of DNA (Fig. 1). Twenty-threemer single-stranded DNAs with the sequences of 5'GAGGCGCTGCCYCCACCATGAGC-3' (named 23-Ys, $\mathrm{Y}=\mathrm{C}, \mathrm{A}, \mathrm{G}$, and $\mathrm{T}$ ) were employed in this work. These sequences are stable in aqueous solution free from any secondary structure at room temperature. In an optimized experiment, the concentration ratio 1:15:75 of DNA/HAuCl$/ 4$ DMAB was used to produce fluorescent Au NCs in PBS at pH 4.4 (Fig. S1 and S2 in the Supporting information). As shown in Fig. 2, the red fluorescent Au NCs can be prepared in aqueous solution by reducing the gold salt with DMAB using single-stranded $23-\mathrm{C}$ as the template. The DNA-

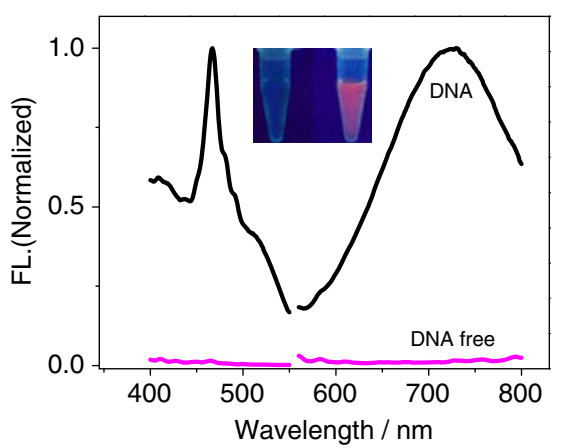

Fig. 2 Fluorescence excitation (measured at $725 \mathrm{~nm}$ ) and emission (excited at $467 \mathrm{~nm}$ ) spectra of $20 \mathrm{mM}$ PBS (pH 4.4) containing $75 \mu \mathrm{M}$ $\mathrm{HAuCl}_{4}$ and $375 \mu \mathrm{M}$ DMAB in the absence and presence of $5 \mu \mathrm{M} 23-\mathrm{C}$. Inset: photographs of the solutions in the absence and presence of DNA (from left to right) under UV illumination 
Fig. 3 TEM images of $\mathrm{Au}$ nanomaterials prepared in PBS at $\mathrm{pH} 4.4$ for $\mathrm{NCs}$ (a) and $\mathrm{pH} 7.0$ for larger nanoparticles (b)
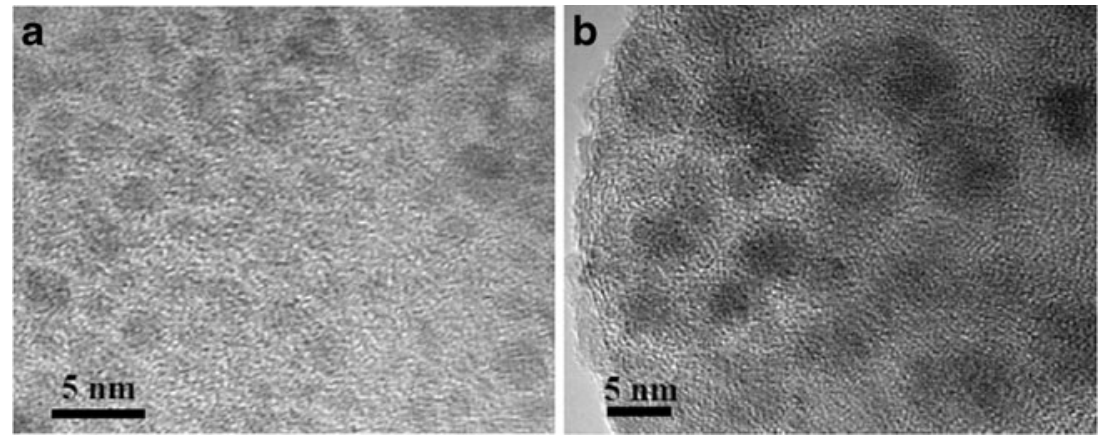

templated $\mathrm{Au}$ NCs display excitation and emission bands at 467 and $725 \mathrm{~nm}$, respectively. However, reducing the $\mathrm{HAuCl}_{4}$ solution by DMAB in the absence of $23-\mathrm{C}$ induces a light pink sample without any noticeable emission, confirming the crucial role of DNA for the formation of fluorescent Au NCs. Under UV illumination, a bright red emission from the asprepared $\mathrm{Au} \mathrm{NC}$ solution can be clearly distinguished from that of the solution without 23-C by the naked eye, indicating that highly fluorescent $\mathrm{Au} \mathrm{NCs}$ are formed in the presence of DNA. Previously, Dickson et al. [5] have explained their experimental results with the spherical Jellium model for predicting the size of $\mathrm{Au} \mathrm{NCs}$ by fitting the Au NCs' emission energy with the scaling relation of $E_{\mathrm{Fermi}} / N^{1 / 3}$, where $E_{\text {Fermi }}$ is the Fermi level of gold element and $N$ is the number of $\mathrm{Au}$ atoms composed of $\mathrm{Au} \mathrm{NCs}$. From the observed emission energy of $1.71 \mathrm{eV}$ in our experiment for the DNA-templated $\mathrm{Au} \mathrm{NCs,} \mathrm{we} \mathrm{roughly} \mathrm{estimate} \mathrm{that}$ the number of gold atoms composed of the Au NCs is about 21. As revealed by the TEM analysis (Fig. 3a), it is difficult to accurately determine the diameter of the fluorescent $\mathrm{Au}$ NCs due to the low TEM contrast with the background for such small-sized materials, which is in good agreement with the cluster dimension predicted by the Jellium model. However, the cluster profile can be easily seen from the TEM image.

We found that many factors strongly affected the formation of fluorescent $\mathrm{Au}$ NCs. As shown in Fig. 4a, the solution $\mathrm{pH}$ plays a key role in modulating the emissions of Au NCs templated by 23-C. By comparison to the emission from the solution prepared in PBS at $\mathrm{pH} 4.4$, the resulting solutions prepared in PBS at pH 5.0 and 6.0 exhibit
1.2- and 3.1-fold decreases in the fluorescence intensities, respectively. However, there is almost unnoticeable fluorescence emission for those prepared in PBS at $\mathrm{pH} 7.0$ and 8.0. Therefore, acidic solution conditions seem to facilitate the creation of fluorescent Au NCs. Absorption spectra were then followed to further confirm the influence of the solution $\mathrm{pH}$ on the formation of fluorescent Au NCs. As shown in Fig. 4b, the solutions prepared at $\mathrm{pH}$ above 6.0 accordingly exhibit clear absorption peaks located at about $525 \mathrm{~nm}$, which suggests the formation of larger gold nanoparticles with characteristic surface plasmon resonance absorption. As an example, the production of such gold nanoparticles at $\mathrm{pH} 7.0$ is thus evidenced by TEM analysis with diameter larger than $5 \mathrm{~nm}$ (Fig. 3b). By contrast, featureless absorption spectra are observed for the solutions prepared at lower $\mathrm{pH}$ values. This fact indicates that the fluorescent $\mathrm{Au}$ NCs produced at the weakly acidic conditions should be smaller than $2 \mathrm{~nm}$ in diameter [57, 58], which is in agreement with the TEM results and the Jellium model-based prediction. Previously, the similar absorption spectra with such featureless behaviors were observed for fluorescent $\mathrm{Au} \mathrm{NCs}$ by their intensities decaying roughly exponentially toward the visible region from the UV region $[14,36,38,39]$. Therefore, the production of fluorescent $\mathrm{Au}$ $\mathrm{NCs}$ is free from the simultaneous formation of large gold nanoparticles at the acidic conditions. On the basis of these observations, our method would expand the potential applications of fluorescent Au NCs with DNA as the biotemplate because the previously reported protein-based synthesis of fluorescent $\mathrm{Au} \mathrm{NCs}$ was mostly carried out at strong alkaline conditions $(\mathrm{pH} \geq 12)[10]$.
Fig. 4 Effects of solution $\mathrm{pH}$ on the formation of fluorescent Au NCs: a fluorescence spectra, b absorption spectra
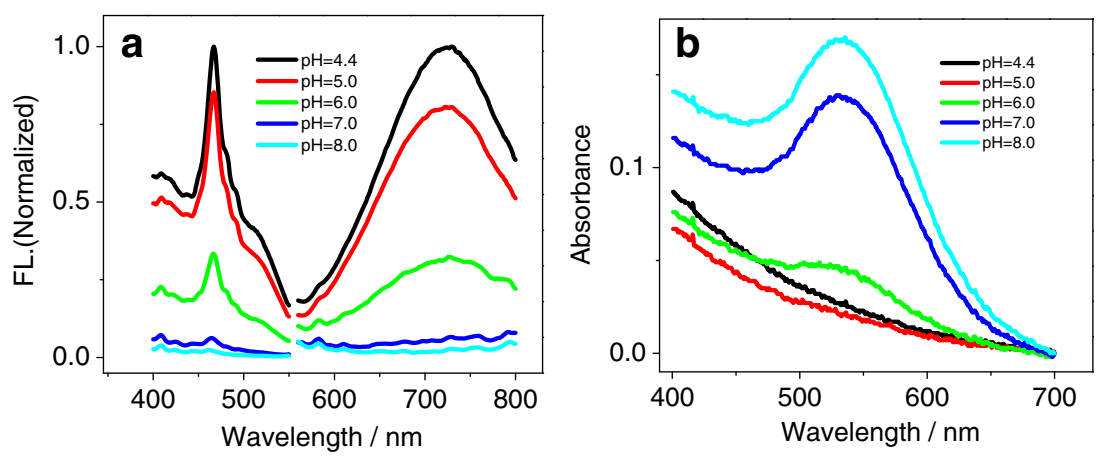
However, the immediate addition of DMAB into the freshly mixed DNA-HAuCl ${ }_{4}$ solution prepared at whatever $\mathrm{pH}$ results in the prompt formation of pink samples without any fluorescence response to be observed. Consequently, we speculate that the first crucial step for the creation of fluorescent $\mathrm{Au}$ NCs is the formation of an $\mathrm{Au}(\mathrm{III})-\mathrm{DNA}$ complex, which occurs by replacing the $\mathrm{Cl}^{-}$ligands in $\mathrm{AuCl}_{4}^{-}$with DNA bases before the reduction. To follow the reaction between $\mathrm{AuCl}_{4}{ }^{-}$and DNA, we monitored the time evolution of the DNA absorption spectra at $260 \mathrm{~nm}$ after the addition of $\mathrm{HAuCl}_{4}$. As shown in Fig. 5, an abrupt decrease in the absorption is evidenced after aging the sample prepared at $\mathrm{pH} 4.4$ for $10 \mathrm{~h}$, whereas there is no distinct change in the absorption for the sample prepared at $\mathrm{pH} 7.0$ even with the reaction time extending up to $50 \mathrm{~h}$. Although the exact interaction mechanism of the DNA base with $\mathrm{HAuCl}_{4}$ is not yet clear, the coordination and chelation between gold and both the ring and amino nitrogens of the nucleic acid bases [59] should contribute to this process. At an acidic solution, cytosine in DNA should be partially protonated [60] to facilitate its interaction with the negatively charged $\mathrm{AuCl}_{4}^{-}$, while at neutral and alkaline conditions, there is a relative large repulsion force to prevent the negatively charged DNA from approaching the negatively charged $\mathrm{AuCl}_{4}{ }^{-}$. The possible protonation of cytosine in DNA would induce less base stacking, which is reflected by the higher absorption at $\mathrm{pH} 4.4$ than that at $\mathrm{pH} 7.0$ as observed at the initial stage of $\mathrm{AuCl}_{4}^{-}$addition (Fig. 5). Nevertheless, the at-least 10-h aging time for the production of fluorescent $\mathrm{Au} \mathrm{NCs}$ at the weakly acidic condition shows that the specific interaction between $\mathrm{AuCl}_{4}{ }^{-}$and DNA is still a slow process. Thus, without the aging step prior to reduction, $\mathrm{Au}$ (III) mainly in the form of $\mathrm{AuCl}_{4}{ }^{-}$free in water can be directly reduced by DMAB into large gold nanoparticles. Further works will be expected in this laboratory to identify the interaction mode of DNA bases with the fluorescent $\mathrm{Au}$ NCs by, for example, infrared and circular dichroism spectra.

It is well known that different DNA sequences and lengths can be used to modulate the emissions of DNA-

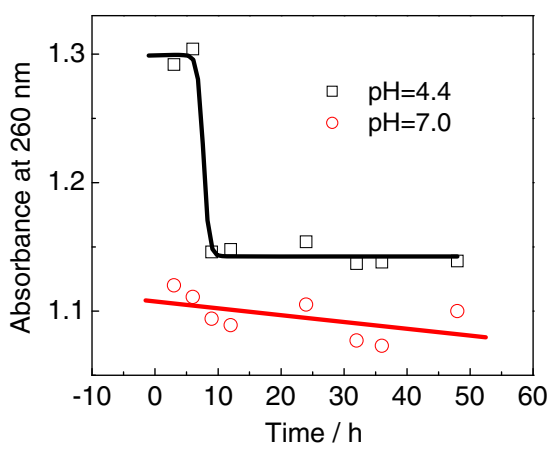

Fig. 5 Time evolutions of the corresponding absorbances at $260 \mathrm{~nm}$ for the $\mathrm{HAuCl}_{4}$-DNA solutions at $\mathrm{pH} 4.4$ and 7.0 before DMAB addition

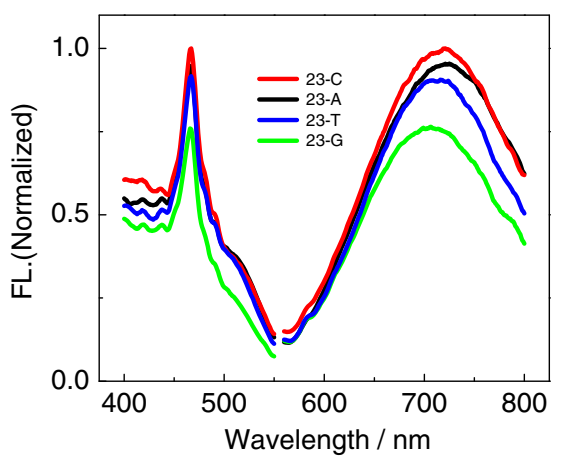

Fig. 6 Dependences of DNA sequences on the fluorescence spectra of the as-prepared $\mathrm{Au} \mathrm{NCs}$

templated silver nanoclusters [54]. Thus, it is expected that the DNA sequences could be also used to tune the Au NCs' emissions. To examine the impact of DNA sequences, we only changed the central base in 23-C from cytosine to adenine (23-A), guanine (23-G), and thymine (23-T) and kept the other reaction conditions unchanged. As shown in Fig. 6, the Au NCs' emissions are dependent on the DNA sequences with the intensities decreasing in the order of 23$\mathrm{C}>23-\mathrm{A}>23-\mathrm{T}>23-\mathrm{G}$. The emission maxima are also blue shifted in the same order. Due to the one-base alteration for all the used DNAs at the same length, small changes in $\mathrm{Au} \mathrm{NCs}^{\prime}$ emissions could be imaged as observed here. Therefore, we believe that it is feasible to synthesize $\mathrm{Au}$ NCs with different emission behaviors by DNA sequence alterations.

We found that the used reductant had a profound effect on the formation of fluorescent Au NCs. For example, replacement of DMAB with $\mathrm{NaBH}_{4}$, a common reductant in the synthesis of noble metal nanoclusters [54], mainly resulted in prompt production of large nanoparticles with barely faint fluorescence even though the aging procedure was still carried out, which is in agreement with the previous observation that $\mathrm{NaBH}_{4}$ was an ineffective reductant for the production of fluorescent $\mathrm{Au}$ NCs [36]. By comparison to

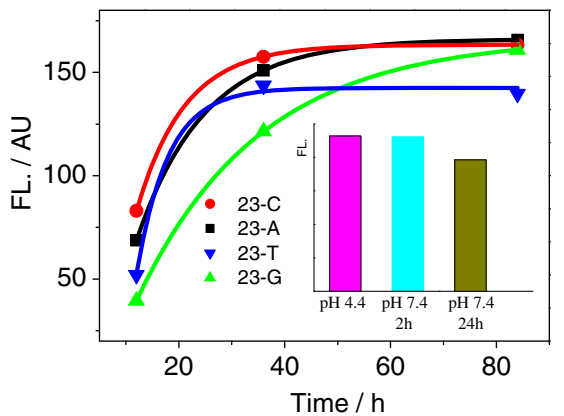

Fig. 7 Time evolutions of the $\mathrm{Au}$ NCs' fluorescence emissions after the addition of DMAB. Inset: the emission intensities of the preformed $\mathrm{Au}$ NCs templated by $23-\mathrm{C}$ at $\mathrm{pH} 4.4$ and then after 2 and $24 \mathrm{~h}$ of adjusting the solution $\mathrm{pH}$ to 7.4 
the strong reduction capacity related to $\mathrm{NaBH}_{4}, \mathrm{DMAB}$ was a weak reductant [61] and proved to be a fine candidate to reduce the DNA-bound gold species to fluorescent $\mathrm{Au} \mathrm{NCs}$. As shown in Fig. 7, an incubation time of $36 \mathrm{~h}$ after the addition of DMAB is needed to get the stable emissions on account of the weak reducing capacity of DMAB at the weakly acidic condition. The formed Au NCs are stable enough to keep their emissions for more than 2 days. Thus, we reasonably conclude that a slow reduction process of the DNA-bound gold species is crucial to prevent the preformed $\mathrm{Au}$ NCs from aggregating into large nanoparticles.

Lastly, we tested the stability of fluorescent Au NCs at the solution with different $\mathrm{pH}$ from that for their preparation. As shown in the inset of Fig. 7, the fluorescence intensities of the preformed $\mathrm{Au} \mathrm{NCs}$ at $\mathrm{pH} 4.4$ decrease only 1 and $15.6 \%$ after 2 and $24 \mathrm{~h}$ of adjusting the solution $\mathrm{pH}$ value to 7.4, indicating that the preformed Au NCs' emission is not seriously affected by electrolyte's $\mathrm{pH}$. Accordingly, we expect that although the fluorescent $\mathrm{Au} \mathrm{NCs}$ can be formed only at the weakly acidic conditions, the high stability of the preformed $\mathrm{Au} \mathrm{NCs}$ at the physiological $\mathrm{pH}$ condition would greatly facilitate their potential use in bioimaging applications due to biocompatibility of the used DNA template.

\section{Conclusion}

In summary, we presented a new approach for the synthesis of water-soluble, red fluorescent Au NCs templated by DNA. Investigations by fluorescence, TEM, and absorption spectra convince that the fluorescent Au NCs can be formed by reducing the Au precursor with DMAB at weakly acidic $\mathrm{pH}$ conditions. During this process, the aging time for completing the interaction of DNA with $\mathrm{HAuCl}_{4}$ before reduction is critical to form the fluorescent $\mathrm{Au}$ NCs. In addition, the Au NCs' emissions could be tuned by DNA sequences. The high stability of the preformed Au NCs at the physiological $\mathrm{pH}$ condition and the biocompatibility of the used DNA template would support their wide applications as novel nanoprobes.

Acknowledgments This study was supported by the National Natural Science Foundation of China (grant no. 21075112), the Zhejiang Provincial Natural Science Foundation of China for Distinguished Young Scholars (grant no. R12B050001), the Foundation of State Key Laboratory of Electroanalytical Chemistry, Changchun Institute of Applied Chemistry (grant no. SKLEAC2010001), and the Scientific Research Foundation for Returning Overseas Chinese Scholars, State Education Ministry.

Open Access This article is distributed under the terms of the Creative Commons Attribution License which permits any use, distribution and reproduction in any medium, provided the original author(s) and source are credited.

\section{References}

1. Zheng J, Nicovich PR, Dickson RM (2007) Highly fluorescent noble metal quantum dots. Annu Rev Phys Chem 58:409-431

2. Lin CAJ, Lee CH, Hsieh JT, Wang HH, Li JK, Shen JL, Chan WH, Yeh HI, Chang WH (2009) Synthesis of fluorescent metallic nanoclusters toward biomedical application: recent progress and present challenges. J Med Biol Eng 29:276-283

3. Yang QF, Liu JY, Chen HP, Wang XX, Huang QM, Shan Z (2011) Preparation of noble metallic nanoclusters and its application in biological detection. Prog Chem 23:880-892

4. Shang L, Dong SJ, Nienhaus GU (2011) Ultra-small fluorescent metal nanoclusters: synthesis and biological applications. Nano Today 6:401-4184

5. Zheng J, Zhang CW, Dickson RM (2004) Highly fluorescent, water soluble, size-tunable, gold quantum dots. Phys Rev Lett 93:077402

6. Zheng J, Petty JT, Dickson RM (2003) High quantum yield blue emission from water-soluble $\mathrm{Au}_{8}$ nanodots. J Am Chem Soc 125:7780-7781

7. Shi X, Ganser TR, Sun K, Balogh LP, Baker JR Jr (2006) Characterization of crystalline dendrimer-stabilized gold nanoparticles. Nanotechnology 17:1072-1078

8. Bao Y, Zhong C, Vu DM, Temirov JP, Dyer RB, Martinez JS (2007) Nanoparticle free synthesis of fluorescent gold nanoclusters at physiological temperature. J Phys Chem C 111:12194-12198

9. Jao YC, Chen MK, Lin SY (2010) Enhanced quantum yield of dendrimer-entrapped gold nanodots by a specific ion-pair association and microwave irradiation for bioimaging. Chem Commun 46:2626-2628

10. Xavier PL, Chaudhari K, Baksi A, Pradeep T (2012) Proteinprotected luminescent noble metal quantum clusters: an emerging trend in atomic cluster nanoscience. Nano Rev 3:14767

11. Xie J, Zheng Y, Ying JY (2009) Protein-directed synthesis of highly fluorescent gold nanoclusters. J Am Chem Soc 131:888-889

12. Wei H, Wang Z, Yang L, Tian S, Hou C, Lu Y (2010) Lysozymestabilized gold fluorescent cluster: synthesis and application as $\mathrm{Hg}^{2+}$ sensor. Analyst 135:1406-1410

13. Hu D, Sheng Z, Gong P, Zhang P, Cai L (2010) Highly selective fluorescent sensors for $\mathrm{Hg}^{2+}$ based on bovine serum albumincapped gold nanoclusters. Analyst 135:1411-1416

14. Kawasaki H, Yoshimura K, Hamaguchi K, Arakawa R (2011) Trypsin-stabilized fluorescent gold nanocluster for sensitive and selective $\mathrm{Hg}^{2+}$ detection. Anal Sci 27:591-596

15. Pu KY, Luo Z, Li K, Xie J, Liu B (2011) Energy transfer between conjugated-oligoelectrolyte-substituted poss and gold nanocluster for multicolor intracellular detection of mercury ion. J Phys Chem C 115:13069-13075

16. Retnakumari A, Setua S, Menon D, Ravindran P, Muhammed H, Pradeep T, Nair S, Koyakutty M (2010) Molecular-receptorspecific, non-toxic, near-infrared-emitting Au cluster-protein nanoconjugates for targeted cancer imaging. Nanotechnology 21:055103

17. Liu Y, Ai K, Cheng X, Huo L, Lu L (2010) Gold-nanoclusterbased fluorescent sensors for highly sensitive and selective detection of cyanide in water. Adv Funct Mater 20:951-956

18. Wen F, Dong Y, Feng L, Wang S, Zhang S, Zhang X (2011) Horseradish peroxidase functionalized fluorescent gold nanoclusters for hydrogen peroxide sensing. Anal Chem 83:1193-1196

19. Durgadas CV, Sharma CP, Sreenivasan K (2011) Fluorescent gold clusters as nanosensors for copper ions in live cells. Analyst 136:933-940

20. Xavier PL, Chaudhari K, Verma PK, Pal SK, Pradeep T (2010) Luminescent quantum clusters of gold in transferrin family protein, lactoferrin exhibiting FRET. Nanoscale 2:2769-2776 
21. Li L, Liu H, Shen Y, Zhang J, Zhu JJ (2011) Electrogenerated chemiluminescence of $\mathrm{Au}$ nanoclusters for the detection of dopamine. Anal Chem 83:661-665

22. Guével XL, Daum N, Schneider M (2011) Synthesis and characterization of human transferrin-stabilized gold nanoclusters. Nanotechnology 22:275103

23. Retnakumari A, Jayasimhan J, Chandran P, Menon D, Nair S, Mony U, Koyakutty M (2011) $\mathrm{CD}_{33}$ monoclonal antibody conjugated $\mathrm{Au}$ cluster nano-bioprobe for targeted flow-cytometric detection of acute myeloid leukaemia. Nanotechnology 22:285102

24. Jin L, Shang L, Guo S, Fang Y, Wen D, Wang L, Yin J, Dong S (2011) Biomolecule-stabilized $\mathrm{Au}$ nanoclusters as a fluorescence probe for sensitive detection of glucose. Biosens Bioelectron 26:1965-1969

25. Yabu H (2011) One-pot synthesis of blue light-emitting Au nanoclusters and formation of photo-patternable composite films. Chem Commun 47:1196-1197

26. Yang X, Shi M, Zhou R, Chen X, Chen H (2011) Blending of $\mathrm{HAuCl}_{4}$ and histidine in aqueous solution: a simple approach to the $\mathrm{Au}_{10}$ cluster. Nanoscale 3:2596-2601

27. Barrientos AG, de la Puente JM, Rojas TC, Fernandez A, Penades S (2003) Gold glyconanoparticles: synthetic polyvalent ligands mimicking glycocalyx-like surfaces as tools for glycobiological studies. Chem Eur J 9:1909-1921

28. Link S, Beeby A, FitzGerald S, El-Sayed MA, Schaaff TG, Whetten RL (2002) Visible to infrared luminescence from a 28atom gold cluster. J Phys Chem B 106:3410-3415

29. Huang T, Murray RW (2001) Visible luminescence of water-soluble monolayer-protected gold clusters. J Phys Chem B 105:12498-12502

30. Shibu ES, Radha B, Verma PK, Bhyrappa P, Kulkarni GU, Pal SK, Pradeep T (2009) Functionalized $\mathrm{Au}_{22}$ clusters: synthesis, characterization, and patterning. ACS Appl Mater Interfaces 1:2199-2210

31. Polavarapu L, Manna M, Xu QH (2011) Biocompatible glutathione capped gold clusters as one- and two-photon excitation fluorescence contrast agents for live cells imaging. Nanoscale 3:429-434

32. Tu X, Chen W, Guo X (2011) Facile one-pot synthesis of nearinfrared luminescent gold nanoparticles for sensing copper (II). Nanotechnology 22:095701

33. Yu M, Zhou C, Liu J, Hankins JD, Zheng J (2011) Luminescent gold nanoparticles with $\mathrm{pH}$-dependent membrane adsorption. J Am Chem Soc 133:11014-11017

34. Liu X, Li C, Xu J, Lv J, Zhu M, Guo Y, Cui S, Liu H, Wang S, Li Y (2008) Surfactant-free synthesis and functionalization of highly fluorescent gold quantum dots. J Phys Chem C 112:10778-10783

35. Kawasaki H, Yamamoto H, Fujimori H, Arakawa R, Iwasaki Y, Inada M (2010) Stability of the DMF-protected Au nanoclusters: photochemical, dispersion, and thermal properties. Langmuir 26:5926-5933

36. Shang L, Dörlich RM, Brandholt S, Schneider R, Trouillet V, Bruns M, Gerthse D, Nienhaus GU (2011) Facile preparation of water-soluble fluorescent gold nanoclusters for cellular imaging applications. Nanoscale 3:2009-2014

37. Shao CY, Yuan B, Wang HQ, Zhou Q, Li Y, Guan Y, Deng Z (2011) Eggshell membrane as a multimodal solid state platform for generating fluorescent metal nanoclusters. J Mater Chem 21:2863-2866

38. Duan HW, Nie SM (2007) Etching colloidal gold nanocrystals with hyperbranched and multivalent polymers: a new route to fluorescent and water-soluble atomic clusters. J Am Chem Soc 129:2412-2413

39. Lin CAJ, Yang TY, Lee CH, Huang SH, Sperling RA, Zanella M, Li JK, Shen JL, Wang HH, Yeh HI, Parak WJ, Chang WH (2009) Synthesis, characterization, and bioconjugation of fluorescent gold nanoclusters toward biological labeling applications. ACS Nano 3:395-401

40. Wang HH, Lin CAJ, Lee CH, Lin YC, Tseng YM, Hsieh CL, Chen $\mathrm{CH}$, Tsai CH, Hsieh CT, Shen JL, Chan WH, Chang WH, Yeh HI
(2011) Fluorescent gold nanoclusters as a biocompatible marker for in vitro and in vivo tracking of endothelial cells. ACS Nano 5:4337-4344

41. Muhammed MAH, Verma PK, Pal SK, Kumar RCA, Paul S, Omkumar RV, Pradeep T (2009) Bright, NIR-emitting $\mathrm{Au}_{23}$ from $\mathrm{Au}_{25}$ : characterization and applications including biolabeling. Chem Eur J 15:10110-10120

42. Qian H, Zhu M, Lanni E, Zhu Y, Bier ME, Jin R (2009) Conversion of polydisperse $\mathrm{Au}$ nanoparticles into monodisperse $\mathrm{Au}_{25}$ nanorods and nanospheres. J Phys Chem C 113:17599-17603

43. Li X, Jiang P, Ge G (2011) Synthesis of small water-soluble gold nanoparticles and their chemical modification into hollow structures and luminescent nanoclusters. Colloid Surf A 384:62-67

44. Bao Y, Yeh HC, Zhong C, Ivanov SA, Sharma JK, Neidig ML, Vu DM, Shreve AP, Dyer RB, Werner JH, Martinez JS (2010) Formation and stabilization of fluorescent gold nanoclusters using small molecules. J Phys Chem C 114:15879-15882

45. Shibu ES, Pradeep T (2011) Quantum clusters in cavities: trapped $\mathrm{Au}_{15}$ in cyclodextrins. Chem Mater 23:989-999

46. Shichibu Y, Konishi K (2010) HCl-induced nuclearity convergence in diphosphine-protected ultrasmall gold clusters: a novel synthetic route to "magic-number" $\mathrm{Au}_{13}$ clusters. Small 6:1216-1220

47. Huang CC, Yang Z, Lee KH, Chang HT (2007) Synthesis of highly fluorescent gold nanoparticles for sensing mercury(II). Angew Chem Int Ed 46:6824-6828

48. Huang CC, Chen CT, Shiang YC, Lin ZH, Chang HT (2009) Synthesis of fluorescent carbohydrate-protected Au nanodots for detection of concanavalin A and Escherichia coli. Anal Chem $81: 875-882$

49. Wu Z, MacDonald MA, Chen J, Zhang P, Jin R (2011) Kinetic control and thermodynamic selection in the synthesis of atomically precise gold nanoclusters. J Am Chem Soc 133:9670-9673

50. Pettibone JM, Hudgens JW (2011) Gold cluster formation with phosphine ligands: etching as a size-selective synthetic pathway for small clusters. ACS Nano 5:2989-3002

51. Zhu ZK, Jin RC (2010) On the ligand's role in the fluorescence of gold nanoclusters. Nano Lett 10:2568-2573

52. Zhou C, Sun C, Yu M, Qin Y, Wang J, Kim M, Zheng J (2010) Luminescent gold nanoparticles with mixed valence states generated from dissociation of polymeric $\mathrm{Au}$ (I) thiolates. J Phys Chem C 114:7727-7732

53. Kamei Y, Shichibu Y, Konishi K (2011) Generation of small gold clusters with unique geometries through cluster-to-cluster transformations: octanuclear clusters with edge-sharing gold tetrahedron motifs. Angew Chem Int Ed 50:7442-7445

54. Díez I, Ras RHA (2011) Fluorescent silver nanoclusters. Nanoscale 3:1963-1970, and references therein

55. Xu H, Suslick KS (2010) Water-soluble fluorescent silver nanoclusters. Adv Mater 22:1078-1082, and references therein

56. Zhou R, Shi M, Chen X, Wang M, Chen H (2009) Atomically monodispersed and fluorescent sub-nanometer gold clusters created by biomolecule-assisted etching of nanometer-sized gold particles and rods. Chem Eur J 15:4944-4951

57. Templeton A, Wuelfing W, Murray R (2000) Monolayer protected cluster molecules. Acc Chem Res 33:27-36

58. Liu C, Ho M, Chen Y, Hsieh C, Lin Y, Wang Y, Yang M, Duan H, Chen B, Lee J (2009) Thiol-functionalized gold nanodots: twophoton absorption property and imaging in vitro. J Phys Chem C 113:21082-21089

59. Gibson DW, Beer M, Barrnett RJ (1971) Gold (III) complexes of adenine nucleotides. Biochemistry 10:3669-3678

60. Nakamoto K, Tsuboi M, Strahan GD (2008) Drug-DNA interactions: structures and spectra. Wiley, USA

61. Watanabe H, Abe S, Honma H (1998) Gold wire bondability of electroless gold plating using disulfiteaurate complex. J Appl Electrochem 28:525-530 